\title{
Modelling microbial exchanges between forms of soil nitrogen in contrasting ecosystems
}

\author{
M. Pansu ${ }^{1}$, D. Machado ${ }^{2}$, P. Bottner ${ }^{3}$, and L. Sarmiento ${ }^{4}$ \\ ${ }^{1}$ IRD, UMR Eco\&Sol (Supagro, Cirad, Inra, IRD), Place Viala, Montpellier, France \\ ${ }^{2}$ Laboratorio de Investigación en Análisis Químico Industrial y Agropecuario, Departamento de Química. Facultad de \\ Ciencias, Universidad de los Andes, Mérida, Venezuela \\ ${ }^{3}$ CEFE-CNRS, Montpellier, France \\ ${ }^{4}$ Instituto de Ciencias Ambientales y Ecológicas, Facultad de Ciencias, Universidad de los Andes, Mérida, Venezuela
}

Correspondence to: M. Pansu (marc.pansu@ird.fr)

Received: 16 January 2013 - Published in Biogeosciences Discuss.: 25 March 2013

Revised: 15 November 2013 - Accepted: 6 January 2014 - Published: 20 February 2014

\begin{abstract}
Although nitrogen (N) is often combined with carbon (C) in organic molecules, $\mathrm{C}$ passes from the air to the soil through plant photosynthesis, whereas $\mathrm{N}$ passes from the soil to plants through a chain of microbial conversions. However, dynamic models do not fully consider the microorganisms at the centre of exchange processes between organic and mineral forms of $\mathrm{N}$. This study monitored the transfer of ${ }^{14} \mathrm{C}$ and ${ }^{15} \mathrm{~N}$ between plant materials, microorganisms, humified compartments, and inorganic forms in six very different ecosystems along an altitudinal transect. The microbial conversions of the ${ }^{15} \mathrm{~N}$ forms appear to be strongly linked to the previously modelled $\mathrm{C}$ cycle, and the same equations and parameters can be used to model both $\mathrm{C}$ and $\mathrm{N}$ cycles. The only difference is in the modelling of the flows between microbial and inorganic forms. The processes of mineralization and immobilization of $\mathrm{N}$ appear to be regulated by a two-way microbial exchange depending on the $\mathrm{C}: \mathrm{N}$ ratios of microorganisms and available substrates. The MOMOS (Modelling of Organic Matter of Soils) model has already been validated for the $\mathrm{C}$ cycle and also appears to be valid for the prediction of microbial transformations of $\mathrm{N}$ forms. This study shows that the hypothesis of microbial homeostasis can give robust predictions at global scale. However, the microbial populations did not appear to always be independent of the external constraints. At some altitudes their $\mathrm{C}: \mathrm{N}$ ratio could be better modelled as decreasing during incubation and increasing with increasing $\mathrm{C}$ storage in cold conditions. The ratio of potentially mineralizable- ${ }^{15} \mathrm{~N} /$ inorganic- ${ }^{15} \mathrm{~N}$ and the ${ }^{15} \mathrm{~N}$ stock in the plant debris and the microorganisms was mod-
\end{abstract}

elled as increasing with altitude, whereas the ${ }^{15} \mathrm{~N}$ storage in stable humus was modelled as decreasing with altitude. This predicts that there is a risk that mineralization of organic reserves in cold areas may increase global warming.

\section{Introduction}

Nitrogen $(\mathrm{N})$ in living plants represents about $5 \%$ of the global N stock; it is adsorbed by plant roots mostly in mineral forms in small quantities in soil where more than $90 \%$ of $\mathrm{N}$ is in organic form (Lin et al., 2000; Pansu and Gautheyrou, 2006). Microbial exchanges play a major role in the $\mathrm{N}$ cycle that must be considered in conjunction with the carbon (C) cycle. Mechanistic models are expected to give an accurate prediction of the transfers of $\mathrm{N}$ between organic and inorganic compartments with varying stability. However, the published models of the $\mathrm{N}$ cycle are not always linked to the $\mathrm{C}$ cycle and are sometimes not fully mechanistic. Manzoni and Porporato (2009) classified them as SIMP for simplified formulations, MIT for mineralization/immobilization turnover mechanisms which assume a transfer of organic to inorganic $\mathrm{N}$ pools before microbial assimilation, DIR for direct microbial assimilation of all available organic N, MIX for models combining DIR and MIT principles, and PAR for a parallel DIR/MIT scheme, which includes direct assimilation and ammonium production by microorganisms, followed by microbial assimilation of the ammonium produced (Barraclough 1997). With increasing knowledge of the 
mechanisms, the types of models available have changed; in $1970,60 \%$ were SIMP and $40 \%$ were MIT, whereas in 2010, $5 \%$ were SIMP, $7 \%$ were MIT, $5 \%$ were MIX, $17 \%$ were PAR, and $66 \%$ were DIR.

Organic $\mathrm{N}$ transformations have often been modelled by considering $\mathrm{C}$ compartments with different $\mathrm{C}: \mathrm{N}$ ratios (e.g. van Veen and Ladd, 1985; Parton et al., 1987; Bradbury et al., 1993; Carter et al., 1993; Dou and Fox, 1995; Quemada and Cabrera, 1995; Richter and Benbi, 1996; Franko, 1996; Mueller et al., 1998; Garnier et al., 2001; Nicolardot et al., 2001; Pansu et al., 2003; 2004; Neill and Gignoux, 2006) but Treseder et al. (2011) called for a better integration of microbial ecology in ecosystem models, and Todd-Brown et al. (2012) considered that "current global models do not represent direct microbial control over decomposition" and called for a new generation of models. An important aspect concerns the stoichiometry of decomposers (Sterner and Elser, 2002). Microbial biomass (MB) has often been considered homeostatic, i.e. with a composition independent of that of the substrates used, implying that assumptions are made to maintain a constant MB $\mathrm{C}: \mathrm{N}$ ratio. However, other models and experimental data (e.g. Wallander et al., 2003; Bottner et al., 2006) allow the $\mathrm{C}: \mathrm{N}$ ratio of $\mathrm{MB}$ to change with time in response to the substrate $\mathrm{C}: \mathrm{N}$ ratio and changes in the microbial communities during decomposition.

This study considers $\mathrm{N}$ dynamics along an altitudinal transect that had previously been used to validate the modelling of the microbial transformations of carbon forms (MOMOSC model, Pansu et al., 2010). The aim was to predict the conversion of the ${ }^{15} \mathrm{~N}$-labelled forms and the conversion of ${ }^{14} \mathrm{C}$ labelled forms simultaneously. This raised questions about the validity of the extensions to the model for the $\mathrm{N}$ cycle. $\mathrm{Can}$ the rates of direct enzymatic $\mathrm{C}$ and $\mathrm{N}$ assimilation be considered to be the same (as in the DIR scheme)? Can the transfers of $\mathrm{C}$ by microbial mortality and respiration cause simultaneous transfers of $\mathrm{N}$ into labile humus and inorganic forms to balance the $\mathrm{MB} \mathrm{C}: \mathrm{N}$ ratio? Can the assimilation of inorganic $\mathrm{N}$ be modelled to sustain microbial activity (MIT scheme) in the case of an $\mathrm{N}$ deficit during conversion of organic forms? Can microorganisms be assumed to assimilate $\mathrm{N}$ from labile and stable organic molecules as well as $\mathrm{N}$ from the inorganic $\mathrm{N}$ pool in realistic modelling of the PAR scheme?

This study also aimed to answer questions about the homeostasis of microorganisms and the stability of the ${ }^{15} \mathrm{~N}$ storage. Is the microbial ${ }^{14} \mathrm{C}:{ }^{15} \mathrm{~N}$ ratio constant or does it vary during incubation periods in different ecosystems at different altitudes? How does ${ }^{15} \mathrm{~N}$ storage tend to change with climate in compartments of different stability?

\section{Materials and methods}

\subsection{The experimental sites}

The experiment was carried out at six sites (Table 1) along an altitudinal transect in Venezuela, at $65-3968 \mathrm{~m}$ above sea level, covering a large bioclimatic gradient that comprised tropical rainforest $(\mathrm{A}(65))$, natural savanna $(\mathrm{A}(165))$, seasonal montane forest $(\mathrm{A}(780))$, cloud forest $(\mathrm{A}(1800))$ and Andean páramo (alpine vegetation) at two heights (A(3400) and $\mathrm{A}(3968)$ ). The sites are described in previous publications (Couteaux et al., 2002; Pansu et al., 2010). This altitudinal transect was characterized by contrasting temperature, annual precipitation and its seasonal distribution and soil characteristics. The long-term mean annual air temperature ranged from $5.5^{\circ} \mathrm{C}$ at $\mathrm{A}(3968)$ to $27.4^{\circ} \mathrm{C}$ at $\mathrm{A}(65)$, the mean annual precipitation ranged from $790 \mathrm{~mm}$ at $\mathrm{A}(3968)$ to $1992 \mathrm{~mm}$ at $\mathrm{A}(1800)$. Soils were acidic at all sites, particularly in the two páramo soils. The soils were loamy at $\mathrm{A}(3400)$, and were sandy loams at the other sites. The savanna soil at site $A(165)$ contained the highest amount of sand and the lowest amount of organic matter, both water holding capacity (WHC) and cation exchange capacity (CEC) were lower than at any of the other sites. The mountain soils $\mathrm{A}(1800)$ and $\mathrm{A}(3400)$ contained the highest amounts of fine particles and organic matter and had the highest WHC and CEC. The three other soils had intermediate WHC and CEC. The carbon content in the $0-10 \mathrm{~cm}$ soil layer varied from $13 \mathrm{~g}(\mathrm{C}) \mathrm{kg}^{-1}$ at $\mathrm{A}(165)$ to more than $100 \mathrm{~g}$ (C) $\mathrm{kg}^{-1}$ (soil) at $\mathrm{A}(1800)$ and $\mathrm{A}(3400)$. The quality of the soil organic matter was also variable, with $\mathrm{C}: \mathrm{N}$ ratios ranging from 13 at $\mathrm{A}(65)$ and $\mathrm{A}(780)$ through 15 at $\mathrm{A}(165)$ up to $17-22$ at the highest sites, $\mathrm{A}(1800)$ to $\mathrm{A}(3968)$.

\subsection{Experimental design and data collection}

Plots with herbaceous vegetation were selected at each site in order to minimize the variability due to the effect of soil cover on microclimate conditions, mainly on soil temperature. Areas with natural vegetation were selected for the savanna and alpine ecosystems but plots on managed grassland were selected for the forest ecosystems. ${ }^{14} \mathrm{C}$ - and ${ }^{15} \mathrm{~N}$ labelled straw was mixed with soil (taken from the top 0 $10 \mathrm{~cm}$ layer at each of the sites) in $14 \times 15 \mathrm{~cm}$ porous bags. The top part of the bags had a $1 \mathrm{~mm}$ mesh to allow the passage of plant roots and mesofauna, and the mesh of the bottom part was $0.1 \mathrm{~mm}$ to minimize losses by gravity. The soil weight per bag was adjusted to reproduce the natural bulk density for a volume of $210 \mathrm{~cm}^{3}$. The labelled straw was obtained by growing the wheat in a labelling chamber with controlled temperature, radiation, humidity, and $\mathrm{CO}_{2}$ concentration. The wheat was grown from seed to maturity in four months in a ${ }^{14} \mathrm{C}$-labelled atmosphere with a ${ }^{15} \mathrm{~N}$-labelled, NPK + micro-nutrient solution. The straw, containing $392 \mathrm{mg}$ $\mathrm{C} \mathrm{g}^{-1}$ and $12.33 \mathrm{mg} \mathrm{N} \mathrm{g}^{-1}$ (C: $\mathrm{N}$ ratio of 31.79), was roughly 
Table 1. Site characteristics.

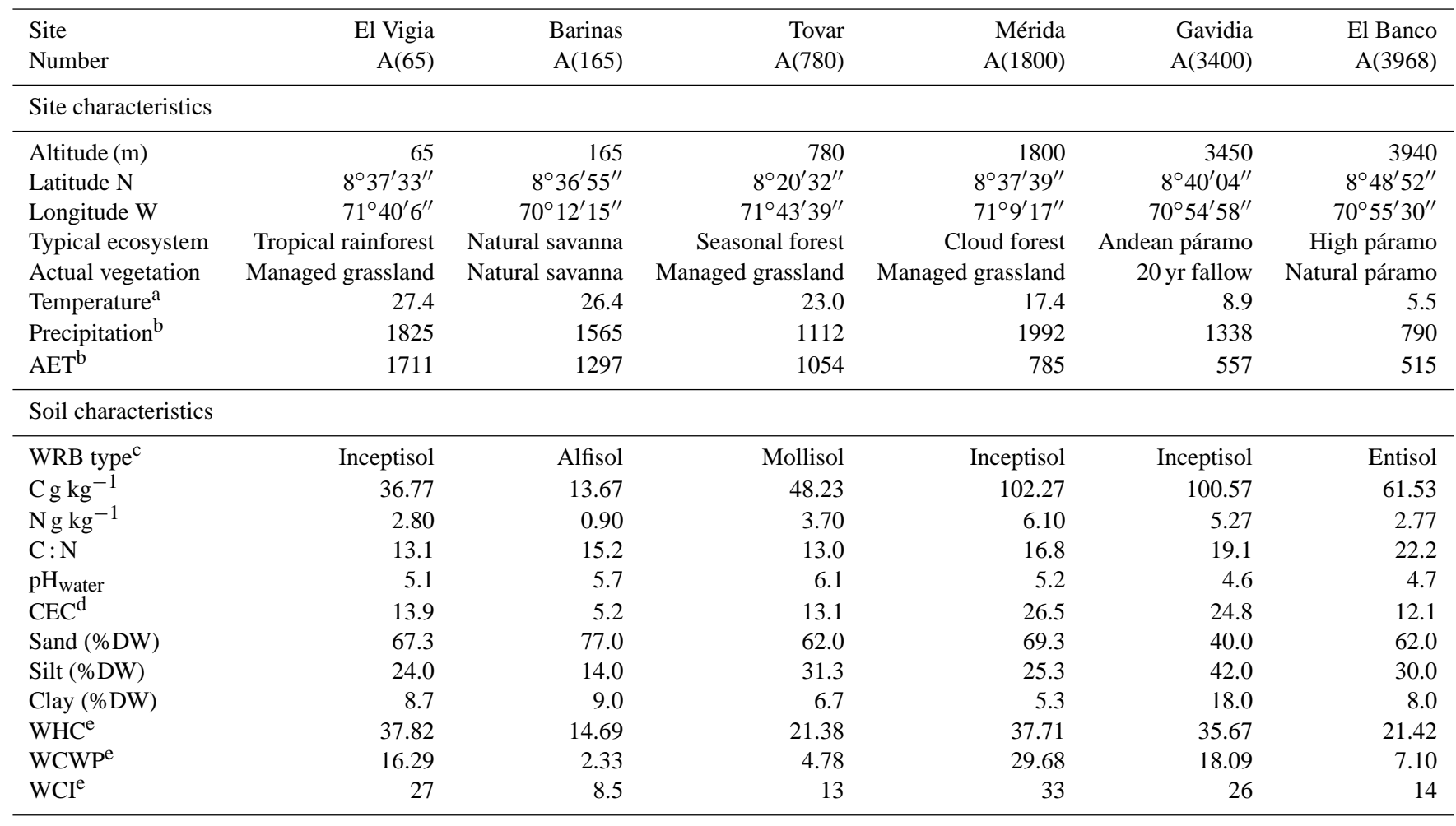

${ }^{\mathrm{a}}$ long-term annual mean temperature in ${ }^{\circ} \mathrm{C} ;{ }^{\mathrm{b}}$ long-term annual mean precipitation and evapotranspiration $(\mathrm{mm}) ;{ }^{\mathrm{c}}$ World Reference Basis; ${ }^{\mathrm{d}}$ cation exchange capacity mmol $(+)$ kg ${ }^{-1} ; \mathrm{e}^{\mathrm{a}}$ water holding capacity, water content at wilting point, and initial water content in soil bags (\% DW).

Table 2. Composition of soil in bags buried in $5-10 \mathrm{~cm}$ soil layer.

\begin{tabular}{|c|c|c|c|c|c|c|c|}
\hline Site & $\begin{array}{r}\text { g straw/ } \\
\text { bag }^{1}\end{array}$ & $\begin{array}{r}\text { mg straw C/ } \\
\text { bag }^{2}\end{array}$ & $\begin{array}{r}\text { mg straw N/ } \\
\text { bag }^{3}\end{array}$ & $\begin{array}{r}\text { g soil }+ \\
\text { straw/bag }{ }^{1}\end{array}$ & $\begin{array}{r}\mathrm{mg} \mathrm{Ng}^{-1} \\
\text { soil + } \text { straw }^{1}\end{array}$ & $\%{ }^{15} \mathrm{~N}^{1}$ & $\begin{array}{l}\%{ }^{15} \mathrm{~N} \\
\text { exces }\end{array}$ \\
\hline $\mathrm{A}(65)$ & 1.08 & 423.36 & 13.32 & 189.32 & 2.88 & 0.6094 & 0.2434 \\
\hline $\mathrm{A}(165)$ & 1.08 & 423.36 & 13.32 & 225.43 & 0.93 & 0.8815 & 0.5155 \\
\hline $\mathrm{A}(780)$ & 0.84 & 329.28 & 10.36 & 151.31 & 3.90 & 0.5347 & 0.1687 \\
\hline $\mathrm{A}(1800)$ & 0.84 & 329.28 & 10.36 & 113.11 & 6.98 & 0.4964 & 0.1304 \\
\hline $\mathrm{A}(3400)$ & 0.48 & 188.16 & 5.92 & 160.97 & 5.40 & 0.4310 & 0.0650 \\
\hline $\mathrm{A}(3968)$ & 0.48 & 188.16 & 5.92 & 182.69 & 2.88 & 0.4857 & 0.1197 \\
\hline
\end{tabular}

ground to $<5 \mathrm{~mm}$ particles. The $\mathrm{N}$ and ${ }^{15} \mathrm{~N}$ composition of the soil in the bags is given in Table 2. The added carbon and nitrogen from the straw ranged from $1.2 \%(\mathrm{~A}(3400))$ to $13.8 \%(\mathrm{~A}(165))$ of the native $\mathrm{C}$ and $0.70 \%(\mathrm{~A}(3400))$ to $6.60 \%(\mathrm{~A}(165))$ of the native $\mathrm{N}$ in the soil.

A total of 40 bags containing the labelled straw and soil were buried $5 \mathrm{~cm}$ deep along four parallel lines in each experimental plot (10 samples at different times $\times 4$ replicates for each sample at each site, making a total of 240 soil bags). When the plots had been set up (23 November to 6 December 1994), the soil bags were moistened with deionized water to the midpoint between WHC and the water content at wilting point (WCWP) (Table 1). On each sampling date, one bag from each of the four lines at each site was selected at random for measurements of the soil water content, total ${ }^{14} \mathrm{C}$ and ${ }^{15} \mathrm{~N}$, and ${ }^{14} \mathrm{C}$ and ${ }^{15} \mathrm{~N}$ in the microbial biomass and inorganic $\mathrm{N}$ stock. The soil bags were left in the soil for 18 months at the two lowest sites $(\mathrm{A}(65)$ and $\mathrm{A}(165)), 24$ months at $\mathrm{A}(780)$, 31 months at $\mathrm{A}(1800)$ and 38 months at the two highest sites (A(3400) and A(3968)). The first samples were taken one month after setting up the experiment and the sampling interval increased with time to six months at the end of the experiment for the highest sites. After collection, the soil bags were stored refrigerated for up to three days before analysis. 
The total $\mathrm{N}$ was determined using Kjeldahl digestion by boiling subsamples in concentrated sulphuric acid with a potassium sulphate-copper sulphate-grey selenium catalyst for $2 \mathrm{~h}$ at $400^{\circ} \mathrm{C}$. The ammonia in the solution was then distilled with sodium hydroxide into a standard $\mathrm{H}_{2} \mathrm{SO}_{4}$ solution and the excess $\mathrm{H}_{2} \mathrm{SO}_{4}$ was determined by back titration with a standard $\mathrm{NaOH}$ solution. After titration, the distillate was acidified to $\mathrm{pH}$ between 3 and 4 to avoid $\mathrm{N}$ losses and evaporated to obtain ammonium sulphate crystals that were analysed for ${ }^{15} \mathrm{~N}$ abundance using mass spectrometry.

The MB $\mathrm{N}$ was determined by fumigation-extraction (Brookes, 1985). After homogenization, a fresh soil sample equivalent to $30 \mathrm{~g}$ dry soil was fumigated with alcohol-free chloroform for $18 \mathrm{~h}$. The fumigated sample and an equivalent control soil sample were treated with $150 \mathrm{~mL}$ of $0.5 \mathrm{~mol}$ $\left(\mathrm{K}_{2} \mathrm{SO}_{4}\right) \mathrm{L}^{-1}$ solution for $30 \mathrm{~min}$ and centrifuged. The extracts were digested, titrated, crystallized and analysed for ${ }^{15} \mathrm{~N}$, as for the determination of total $\mathrm{N}$. The N-labelled part of the microbial biomass was calculated as the difference between the labelled $\mathrm{N}$ in the fumigated and the control samples, corrected by a $K_{\mathrm{N}}$ factor of 0.54 (Joergensen and Mueller, 1996). An aliquot of the extracted solution from the unfumigated samples was used to determine the total inorganic $\mathrm{N}$ and ${ }^{15} \mathrm{~N}$ abundance (ammonium and nitrate separately).

For all compartments (total soil, microbial biomass and mineral nitrogen) the percentage of the $\mathrm{N}$ in the samples that had come from the $\mathrm{N}$ added in the straw (\%Ndff) was calculated as

$\% \mathrm{Ndff}=\frac{\% E_{\text {comp }}}{\% E_{\text {straw }}} \cdot 100$,

where $\% E_{\text {comp }}$ is the atom percent excess of the tracer in the compartment and $\% E_{\text {straw }}$ is the atom percent excess in the straw. From this, the amount of $\mathrm{N}$ from the straw in each compartment was calculated as

$\operatorname{mgN}=\frac{\% \mathrm{Ndff} \cdot \mathrm{N}_{\text {total }}}{100}$,

where $\mathrm{N}_{\text {total }}$ is the total $\mathrm{N}$ in the sample in $\mathrm{mg}$.

Following the death of our colleague, Pierre Bottner, we recovered most of the experimental data, except the last results for microbial biomass (MB) and inorganic ${ }^{15} \mathrm{~N}$, where only the first five results were available for each site.

All ${ }^{15} \mathrm{~N}$-labelled data and ${ }^{14} \mathrm{C}$-labelled data (Pansu et al., 2010) are expressed as a fraction of the labelled $\mathrm{N}$ and $\mathrm{C}$ added at the start of the experiment. As the labelled inorganic $\mathrm{N}$ in the soil bags was very low compared to the total labelled ${ }^{15} \mathrm{~N}$, the total labelled ${ }^{15} \mathrm{~N}$ was considered to be the labelled organic ${ }^{15} \mathrm{~N}$, the difference between the ${ }^{15} \mathrm{~N}$ added in the straw and the organic ${ }^{15} \mathrm{~N}$ being the production of inorganic ${ }^{15} \mathrm{~N}$ which was assumed to have been lost mostly by root uptake, leaching, and gaseous losses through the porous soil bags.

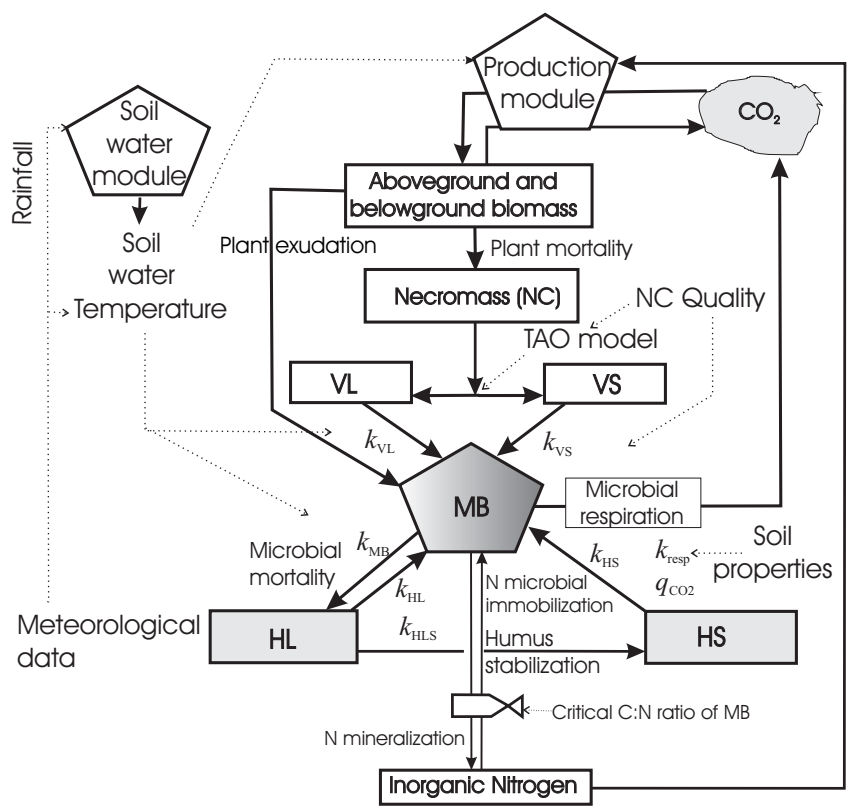

Fig. 1. Flow diagram for the MOMOS model coupled with a soil water module and a production module; $\mathrm{MB}$ is the microbial biomass, VL is the labile necromass (NC), VS is the stable necromass (NC); HL is the labile humus, HS is the stable humus; see table 3 for meaning of the $k$ parameters.

The soil water content was measured in each soil bag using four $5 \mathrm{~g}$ replicates that were dried at $105^{\circ} \mathrm{C}$ for $24 \mathrm{~h}$. Other soil analyses were performed using standard methods (Pansu and Gautheyrou, 2006).

\subsection{The decomposition model MOMOS}

As carbon and nitrogen are closely associated in living organisms, it was assumed that the nitrogen cycle could be modelled in MOMOS-N in the same way as the carbon cycle in MOMOS-C (Pansu et al., 2004, 2010), using a subscript $e$ (either $\mathrm{C}$ or $\mathrm{N}$ ) to distinguish between the elements in the model.

MOMOS (Fig. 1) was defined as a five-compartment model centred on the activity of soil microbial biomass $\left(\mathrm{MB}_{e}\right)$ that grows by assimilation of labile $\left(\mathrm{VL}_{e}\right)$ and stable $\left(\mathrm{VS}_{e}\right)$ fractions of plant necromass $\left(\mathrm{NC}_{e}\right)$ as well as labile $\left(\mathrm{HL}_{e}\right)$ and stable $\left(\mathrm{HS}_{e}\right)$ fractions of humus. The microbial mortality regulates humus formation. The only process which is considered more chemical than biological is the humus stabilization from $\mathrm{HL}_{e}$ to $\mathrm{HS}_{e}$, which is in agreement with observations of Kemmitt et al. (2008). The only difference between the $\mathrm{C}$ and $\mathrm{N}$ models is in the outputs from $\mathrm{MB}_{e}$ to inorganic forms of $\mathrm{C}\left(\mathrm{CO}_{2}-\mathrm{C}\right)$ and $\mathrm{N}\left(\mathrm{NH}_{4}-\mathrm{N}\right)$ or possibly inputs from inorganic $\mathrm{N}$ into $\mathrm{MB}_{\mathrm{N}}$. MOMOS has only seven first-order kinetic parameters (dimension day $^{-1}$ ) and does not need the partitioning coefficients used in other decomposition models. Assuming that the rates of enzymatic 
Table 3. Parameter values used in the MOMOS-C model (Pansu et al., 2010) and retained in this N study.

\begin{tabular}{|c|c|c|c|c|c|c|c|c|c|}
\hline Parameter & Definition & Units & Reference & Values & & & & & \\
\hline & & & & $\mathrm{A}(65)$ & $\mathrm{A}(165)$ & $\mathrm{A}(780)$ & $\mathrm{A}(1800)$ & $\mathrm{A}(3400)$ & $\mathrm{A}(3968)$ \\
\hline$f_{\mathrm{s}}$ & $\begin{array}{l}\text { Stable C fraction of } \\
\text { added NC }\end{array}$ & none & $\begin{array}{l}\text { TAO model, Thuriès et al. (2002); } \\
\text { Pansu and al. (2003); Kaboré et } \\
\text { al. (2012) }\end{array}$ & \multicolumn{6}{|c|}{0.144} \\
\hline$k_{\mathrm{VL}}$ & $\begin{array}{l}\text { Microbial assimilation } \\
\text { rate of labile NC }\end{array}$ & $\operatorname{day}^{-1}$ & $\begin{array}{l}\operatorname{MAX}\left(0.65-0.0019 \eta_{\mathrm{NC}}, 0.1\right) \\
\text { Bottner et al. (2006) }\end{array}$ & \multicolumn{6}{|c|}{0.590} \\
\hline$k_{V S}$ & $\begin{array}{l}\text { microbial assimilation } \\
\text { rate of stable } \mathrm{NC}\end{array}$ & day $^{-1}$ & $\begin{array}{l}\operatorname{MAX}\left(0.0037-0.000026 \eta_{\mathrm{NC}}, 0.00005\right) \\
\text { Bottner et al. }(2006)\end{array}$ & \multicolumn{6}{|c|}{0.0028} \\
\hline$k_{\mathrm{HL}}$ & $\begin{array}{l}\text { Microbial assimilation } \\
\text { rate of labile humus }\end{array}$ & day $^{-1}$ & $\begin{array}{l}0.05 \\
\text { Pansu et al. (2004) }\end{array}$ & \multicolumn{6}{|c|}{0.05} \\
\hline$k_{\mathrm{HS}}$ & $\begin{array}{l}\text { Microbial assimilation } \\
\text { rate of stable humus }\end{array}$ & $\mathrm{day}^{-1}$ & $\begin{array}{l}0.00005 \\
\text { Pansu et al. (2004) }\end{array}$ & \multicolumn{6}{|c|}{0.00005} \\
\hline$k_{\mathrm{HLS}}$ & $\begin{array}{l}\text { Rate of stabilization of } \\
\text { HL to HS }\end{array}$ & day $^{-1}$ & $\begin{array}{l}0.0003 \\
\text { Pansu et al. (2004) }\end{array}$ & \multicolumn{6}{|c|}{0.0003} \\
\hline$k_{\mathrm{MB}}$ & Mortality rate of $\mathrm{MB}$ & day $^{-1}$ & $\begin{array}{l}\operatorname{MIN}\left(0.42+0.0012 \eta_{\mathrm{NC}}, 0.8\right) \\
\text { Bottner et al. }(2006)\end{array}$ & \multicolumn{6}{|c|}{0.458} \\
\hline$k_{\text {resp }}$ & Microbial respiration & day $^{-1}$ & $\begin{array}{l}-0.0008 \mathrm{~F}_{0-20}+0.062 \\
\text { Pansu et al. }(2007) ; 2010\end{array}$ & 0.029 & 0.038 & 0.034 & 0.029 & 0.021 & 0.022 \\
\hline$C_{\mathrm{MB}}^{0}$ & MB-C at steady state & $\begin{array}{l}\mathrm{g} \mathrm{MB}-{ }^{14} \mathrm{Cg}^{-1} \\
\text { added- }-{ }^{14} \mathrm{C}\end{array}$ & Pansu et al. $(2007,2010)$ & 0.0107 & 0.0106 & 0.0192 & 0.0129 & 0.0185 & 0.0156 \\
\hline
\end{tabular}

$\mathrm{MB}$ is microbial biomass, $\mathrm{NC}$ is added necromass, $\eta_{\mathrm{NC}}$ is the $\mathrm{NC} \mathrm{C}: \mathrm{N}$ ratio.

assimilation of organic substrates are the same for $\mathrm{C}$ and $\mathrm{N}$ (see introduction), we attempted to describe the $\mathrm{N}$ cycle for each of the six ecosystems by using the optimal values of parameters previously adjusted for the $\mathrm{C}$ cycle (Table 3). All the $\mathrm{C}$ and $\mathrm{N}$ parameters are linked to soil functions of temperature and water content, ranging from $0-1$, in the general MOMOS equation:

$\dot{\boldsymbol{x}}_{e}=f(T) f(\theta) \mathbf{A}_{e} \boldsymbol{x}_{e}+\boldsymbol{B}_{e}$,

where $\boldsymbol{x}_{e}$ is the vector of the state variables $\left({ }^{14} \mathrm{C}\right.$ or ${ }^{15} \mathrm{~N}$ content of the compartments), $\dot{\boldsymbol{x}}_{e}$ is the vector of the derivatives of $\boldsymbol{x}_{e}, \mathbf{A}_{e}$ is the model parameter matrix for each organic element, $\boldsymbol{B}_{e}$ is a vector determining the external $\mathrm{C}$ and $\mathrm{N}$ inputs (see Pansu et al., 2009 for $\mathrm{C}$ inputs from living roots; $\boldsymbol{B}_{e}=0$ for ${ }^{14} \mathrm{C}$ and ${ }^{15} \mathrm{~N}$-labelled data in this experiment) and $f(T)$ is an exponential function of temperature (Pansu et al., 2010):

$f(T)=Q_{10}^{\left(T-T_{\mathrm{opt}}\right) / 10}$

where $T$ is the actual daily temperature of soil $(0-10 \mathrm{~cm}$ layer) set equal to the air temperature; $T_{\text {opt }}$ is the optimum decomposition temperature, set to $28^{\circ} \mathrm{C}$ (a temperature often used to perform laboratory experiments under optimum conditions; Thuriès et al., 2002), just above the mean annual temperature of the warmer sites $\mathrm{A}(65)$ and $\mathrm{A}(165)$ of this study; $Q_{10}$ is the factor by which the rate increases with a $10^{\circ} \mathrm{C}$ increase in temperature (this was set to 2.2 for all sites for this study; see discussion in Pansu et al., 2010); and $f(\theta)$ is the response function to soil moisture expressed as a fraction of the WHC (Table 1, see discussion in Pansu et al., 2010):

$f(\theta)=\operatorname{MIN}\left(\frac{\theta}{\mathrm{WHC}}, 1\right)$.
The soil water content, $\theta$, was predicted using the SAHEL model (Penning de Vries et al., 1989). This model calculates the daily water content for each soil layer using meteorological data (daily minimum and maximum temperature, precipitation, and latitude), WHC (Table 1) and plant cover as inputs. SAHEL was calibrated for each site using the water content of the soil in the soil bags, and the daily water content values for the $0-10 \mathrm{~cm}$ layer were generated (Pansu et al., 2004). The meteorological data for the experimental periods were collected from the local weather station at each site, or estimated from the nearest stations and archives of data using a transition probability matrix as described in Pansu et al., (2010).

The model matrices $A_{\mathrm{C}}$ and $A_{\mathrm{N}}$ are

$\mathbf{A}_{\mathrm{C}}=\left[\begin{array}{ccccc}-k_{\mathrm{VL}} & 0 & 0 & 0 & 0 \\ 0 & -k_{\mathrm{VS}} & 0 & 0 & 0 \\ k_{\mathrm{VL}} & k_{\mathrm{VS}} & -\left(q_{\mathrm{CO}_{2}}+k_{\mathrm{MB}}\right) & k_{\mathrm{HL}} & k_{\mathrm{HS}} \\ 0 & 0 & k_{\mathrm{MB}} & -\left(k_{\mathrm{HL}}+k_{\mathrm{HLS}}\right) & 0 \\ 0 & 0 & 0 & k_{\mathrm{HLS}} & -k_{\mathrm{HS}}\end{array}\right]$

and

$\mathbf{A}_{\mathrm{N}}=\left[\begin{array}{ccccc}-k_{\mathrm{VL}} & 0 & 0 & 0 & 0 \\ 0 & -k_{\mathrm{VS}} & 0 & 0 & 0 \\ k_{\mathrm{VL}} & k_{\mathrm{VS}}-\left(f\left(x_{\mathrm{C}, \mathrm{MB}} x_{\mathrm{N}, \mathrm{MB}}\right) / f(T) f(\theta) x_{\mathrm{N}, \mathrm{MB}}+k_{\mathrm{MB}}\right) & k_{\mathrm{HL}} & k_{\mathrm{HS}} \\ 0 & 0 & k_{\mathrm{MB}} & -\left(k_{\mathrm{HL}}+k_{\mathrm{HLS}}\right) & 0 \\ 0 & 0 & 0 & k_{\mathrm{HLS}} & -k_{\mathrm{HS}}\end{array}\right]$

The vectors $\boldsymbol{x}_{\mathrm{C}}$ and $\boldsymbol{x}_{\mathrm{N}}$ of the $\mathrm{C}$ and $\mathrm{N}$ concentrations in each compartment are

$\boldsymbol{x}_{\mathrm{C}}=\left[\begin{array}{c}x_{\mathrm{C}, \mathrm{VL}} \\ x_{\mathrm{C}, \mathrm{VS}} \\ x_{\mathrm{C}, \mathrm{MB}} \\ x_{\mathrm{C}, \mathrm{HL}} \\ x_{\mathrm{C}, \mathrm{HS}}\end{array}\right] \boldsymbol{x}_{\mathrm{N}}=\left[\begin{array}{c}x_{\mathrm{N}, \mathrm{VL}} \\ x_{\mathrm{N}, \mathrm{VS}} \\ x_{\mathrm{N}, \mathrm{MB}} \\ x_{\mathrm{N}, \mathrm{HL}} \\ x_{\mathrm{N}, \mathrm{HS}}\end{array}\right]$ 
and the $\mathrm{C}: \mathrm{N}$ ratios of each compartment are $\mathrm{C}: \mathrm{N}_{i}=\frac{\boldsymbol{x}_{\mathrm{C}, i}}{\boldsymbol{x}_{\mathrm{N}, i}}$.

For each incubation period, the derivative of $\mathrm{C}$ is ${ }^{1}$

$\dot{\mathrm{C}}=\sum_{i=1}^{5} \dot{x}_{i, \mathrm{C}}=-f(T) f(\theta) q \mathrm{CO}_{2} x_{\mathrm{C}, \mathrm{MB}}$,

where $q \mathrm{CO}_{2}$ is the metabolic quotient of the microbial biomass:

$q \mathrm{CO}_{2}=k_{\mathrm{resp}} \frac{x_{\mathrm{MB}}}{C_{\mathrm{MB}}^{0}}$,

where $k_{\text {resp }}$ is the respiration coefficient, (dimension day ${ }^{-1}$ ) scaled by $C_{\mathrm{MB}}^{0}$, the biomass at steady state (estimated on untreated soil without recent addition of substrate. In this case, $C_{\mathrm{MB}}^{0}$ was estimated from the values of $\mathrm{MB}-{ }^{14} \mathrm{C}$ measured at the end of incubation).

For each incubation period, the derivative of the total organic $\mathrm{N}$ is the negative of the derivative of total inorganic $\mathrm{N}$ and is expressed by

$\dot{\mathrm{N}}=\sum_{i=1}^{5} \dot{x}_{i, \mathrm{~N}}=-f\left(x_{\mathrm{C}, \mathrm{MB}}, x_{\mathrm{N}, \mathrm{MB}}\right)$,

where positive values of the function $f\left(x_{\mathrm{C}, \mathrm{MB}}, x_{\mathrm{N}, \mathrm{MB}}\right)$ correspond to $\mathrm{N}$ mineralization of microbial $\mathrm{N}$ and negative values correspond to microbial immobilization of inorganic $\mathrm{N}$.

As the simulation concerned only the ${ }^{14} \mathrm{C}$ and ${ }^{15} \mathrm{~N}$ introduced in the straw, the initial conditions for $\mathrm{C}$ and $\mathrm{N}$ compartments of microbial origin were set to zero. If $\mathrm{C}_{0}$ is the amount of added ${ }^{14} \mathrm{C}$ ( $=1$ for data scaled by the ${ }^{14} \mathrm{C}$ input) and $f_{\mathrm{S}}$ is its stable fraction, the initial conditions for the ${ }^{14} \mathrm{C}$ simulation were given by

$x_{\mathrm{C}, \mathrm{VL}}(0)=\left(1-f_{\mathrm{S}}\right) \mathrm{C}_{0}, x_{\mathrm{C}, \mathrm{vS}}(0)=f_{\mathrm{S}} \mathrm{C}_{0}$,

$x_{\mathrm{C}, \mathrm{MB}}(0)=x_{\mathrm{C}, \mathrm{HL}}(0)=x_{\mathrm{C}, \mathrm{HS}}(0)=0$.

The stable fraction, $f_{\mathrm{S}}$, was estimated as that of the stable compartment of the TAO (Transformation of Added Organic materials) model (Thuriès et al., 2002) between $f_{\mathrm{S}}$ and biochemical composition of straw, which gave $f_{\mathrm{S}}=0.14$. If $\eta_{\mathrm{NC}}$ is the $\mathrm{C}: \mathrm{N}$ ratio of labelled $\mathrm{NC}$, and $\eta_{\mathrm{VS}}$ the $\mathrm{C}: \mathrm{N}$ ratio of the stable fraction of $\mathrm{NC}$, the initial conditions for the ${ }^{15} \mathrm{~N}$ simulation were given by

$x_{\mathrm{N}, \mathrm{VL}}(0)=\left(\frac{1}{\eta_{\mathrm{NC}}}-\frac{f s}{\eta_{\mathrm{VS}}}\right) \mathrm{C}_{0}, x_{\mathrm{N}, \mathrm{VS}}(0)=\frac{f s}{\eta_{\mathrm{VS}}} \mathrm{C}_{0}$,

$x_{\mathrm{N}, \mathrm{MB}}(0)=x_{\mathrm{N}, \mathrm{HL}}(0)=x_{\mathrm{N}, \mathrm{HS}}(0)=0$.

For each incubation period, the model assumes that inorg ${ }^{15} \dot{\mathrm{N}}$, the inorganic ${ }^{15} \mathrm{~N}$ remaining in the porous soil

\footnotetext{
${ }^{1}$ The Eq. (5) previously given for MOMOS-C (Pansu et al., 2010) had an optimum $\dot{C}$ which must be multiplied by $f(T) f(\theta)$ to give $\dot{\mathrm{C}}$ adjusted for weather conditions. $q \mathrm{CO}_{2}$ on the right-hand scale of Figs. 3c-8c of Pansu et al. (2010) must be changed to $f(T) f(\theta) q \mathrm{CO}_{2}$
}

bags, is the mineralized ${ }^{15} \mathrm{~N}\left(-\dot{\mathrm{N}}\right.$, Eq. 7) less the ${ }^{15} \mathrm{~N}$ lost from the bag by root uptake, leaching or gaseous losses, which was modelled using a total loss rate $k_{1}$ :

inorg ${ }^{15} \dot{\mathrm{N}}=-\dot{\mathrm{N}}\left(1-k_{1}\right)$ if $\operatorname{inorg}{ }^{15} \mathrm{~N}>0$;

otherwise, inorg ${ }^{15} \dot{\mathrm{N}}=0$ if inorg ${ }^{15} \mathrm{~N} \leq 0$.

\subsection{Assumptions and strategies tested for simulation of N flows}

The function $f\left(x_{\mathrm{C}, \mathrm{MB}}, x_{\mathrm{N}, \mathrm{MB}}\right)$ of equation 7 was defined in terms of $\eta_{\mathrm{MB}}^{\lim }$, the target value for the $\mathrm{C}: \mathrm{N}$ ratio of the $\mathrm{MB}$ $\left(\eta_{\mathrm{MB}}\right)$. The aim was to test the significance of exchanges ( $\mathrm{N}$ immobilization and $\mathrm{N}$ mineralization) between $\mathrm{MB}$ and inorganic $\mathrm{N}$, as modelled in MOMOS, using data for $\mathrm{MB}^{-15} \mathrm{~N}$ and inorganic $-{ }^{15} \mathrm{~N}$. Two assumptions were tested:

1. The MB C:N ratio remains constant throughout incubation (microorganism homeostasis):

$$
f\left(x_{\mathrm{C}, \mathrm{MB}}, x_{\mathrm{N}, \mathrm{MB}}\right)=x_{\mathrm{N}, \mathrm{MB}}-\frac{x_{\mathrm{C}, \mathrm{MB}}}{\eta_{\mathrm{MB}}^{\lim }} \text {. }
$$

For this function, only one parameter, $\eta_{\mathrm{MB}}$, has to be fitted for each site, all the other parameters being those fitted for ${ }^{14} \mathrm{C}$ simulations (Table 3 ).

2. The MB $\mathrm{C}: \mathrm{N}$ ratio decreases linearly with incubation time from $\eta_{\mathrm{MB}}^{\max }$ at the beginning of experiment to $\eta_{\mathrm{MB}}^{\min }$ at incubation time $t_{\mathrm{c}}$ (succession in the decomposer chain with associated changes in $\mathrm{C}: \mathrm{N}$ ratios), and then remains constant at $\eta_{\mathrm{MB}}^{\min }$ after $t_{\mathrm{c}}$ :

$$
\begin{aligned}
& f\left(x_{\mathrm{C}, \mathrm{MB}}, x_{\mathrm{N}, \mathrm{MB}}\right)=x_{\mathrm{N}, \mathrm{MB}}-\frac{x_{\mathrm{C}, \mathrm{MB}}}{\eta_{\mathrm{MB}}^{\max }-\left(\eta_{\mathrm{MB}}^{\max }-\eta_{\mathrm{MB}}\right)_{\mathrm{c}}} \text { for } t<=t_{\mathrm{c}} \\
& \text { otherwise, } f\left(x_{\mathrm{C}, \mathrm{MB}}, x_{\mathrm{N}, \mathrm{MB}}\right)=x_{\mathrm{N}, \mathrm{MB}}-\frac{x_{\mathrm{C}} \min }{\eta_{\mathrm{MB}}^{\min }} \text { for } t>t_{\mathrm{c}} .
\end{aligned}
$$

For this function three parameters must be fitted for each site: $\eta_{\mathrm{MB}}^{\max }, \eta_{\mathrm{MB}}^{\min }$, and $t_{\mathrm{c}}$

Two alternative simulation strategies were also tested: (a) simulated values of $\mathrm{MB}{ }^{15} \mathrm{~N}$ and inorganic ${ }^{15} \mathrm{~N}$ were $\lim$ ited to positive values and (b) negative simulated values for $\mathrm{MB}{ }^{15} \mathrm{~N}$ and inorganic ${ }^{15} \mathrm{~N}$ were allowed. Strategy (b) was used for assumption 1, i.e. that the MB $\mathrm{C}: \mathrm{N}$ ratio was constant (although the model did not calculate many negative values, except at the start of simulation), both strategies were tested for assumption 2, i.e. that the $\mathrm{C}: \mathrm{N}$ ratio decreased. Simulated negative values did not, of course, indicate that the ${ }^{15} \mathrm{~N}$ content was really negative, but rather that ${ }^{14} \mathrm{~N}$ could replace ${ }^{15} \mathrm{~N}$ to supply the nitrogen requirement.

The Powell optimization method was used to estimate the values of $\eta_{\mathrm{MB}}^{\lim }, \eta_{\mathrm{MB}}^{\max }, \eta_{\mathrm{MB}}^{\min }, t_{\mathrm{c}}$, and $k_{1}$ for the six experimental sites. The values of the other parameters (Table 3) remained unchanged from MOMOS-C calibration (Pansu et al., 2004) and validation (Pansu et al., 2010). The model was developed and optimized using VENSIM 5.6b (http: //www.vensim.com). 

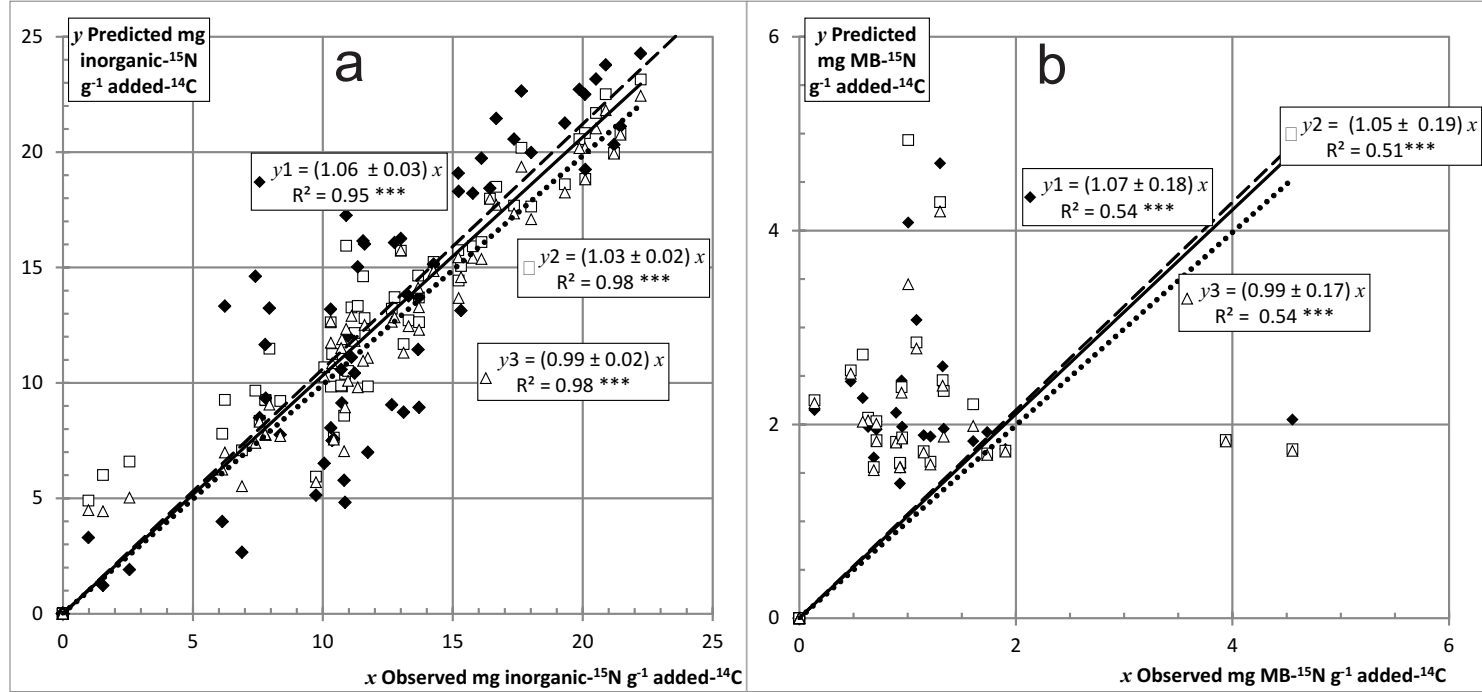

Fig. 2. Model predictions vs. observed values for the whole data set of (a) inorganic ${ }^{15} \mathrm{~N}$, and (b) MB- ${ }^{15} \mathrm{~N}$ : ( $y 1$ ) assumption 1 (dashed line), (y2) assumption 2 and strategy (a) (solid line), or (y3) assumption 2 and strategy (b) (dotted lines).

\subsection{Accuracy tests}

The significance of the MOMOS simulations compared to the mean of measured values was tested by

$F=\frac{\sum_{i=1}^{n}\left(\bar{y}_{i}-\bar{y}\right)^{2} /(n-1)}{\sum_{i=1}^{n}\left(\bar{y}_{i}-\hat{y}_{i}\right)^{2} /(n-p)}$,

where $i=1, \ldots n$ is the number of sampling occasions $(n=$ $11), p$ the number of model parameters which were specifically adjusted to predict the total production of inorganic ${ }^{15} \mathrm{~N}$ ( $p=1$ for assumption $1, p=3$ for assumption 2 ), $\bar{y}_{i}$ is the measured total remaining ${ }^{15} \mathrm{~N}$ at $i, \hat{y}_{i}$ is the corresponding MOMOS predicted value with assumption 1 or 2 and $\bar{y}$ is the mean of the data series for each site.

The graphs in Figs. 3-5 show whether the predicted values were within or outside the confidence intervals of the corresponding data series.

$F$ tests were performed using $\operatorname{RSS}_{T}$, the residual sum of squares between the measured values and the values predicted by MOMOS for assumptions 1 and 2 (Table 4):

$F_{y_{\mathrm{A} 12}}=\frac{\operatorname{RSS}_{\mathrm{A} 1}}{\operatorname{RSS}_{\mathrm{A} 2}}=\frac{\sum_{i=1}^{n}\left(\bar{y}_{i}-\hat{y}_{i \mathrm{~A} 1}\right)^{2} /(n-1)}{\sum_{i=1}^{n}\left(\bar{y}_{i}-\hat{y}_{\mathrm{A} 2}\right)^{2} /(n-3)}$,

where $y_{\mathrm{A} 1}$ and $y_{\mathrm{iA} 2}$ were the predicted values for assumptions 1 and 2, respectively.

An $F$ value (Eq. 14) greater than $F_{(n, n-p)}^{0.05}$ indicates that assumption 1 must be rejected at $5 \%$ significance level; $\mathrm{RSS}_{\mathrm{A} 1}$ was significantly greater than $\mathrm{RSS}_{\mathrm{A} 2}$, and so assumption 1 predictions were significantly less accurate than assumption 2 predictions. A non-significant $F$ test (Eq. 14) showed that the two assumptions did not give significantly different predictions. The test was performed on the whole data set for all six sites and on data for each site (Burnham and Anderson, 1998). Predicted vs. measured values were plotted, and straight lines were fitted to test the overall robustness of predictions for inorganic and $\mathrm{MB}{ }^{15} \mathrm{~N}$ (Fig. 2). Confidence intervals of the intercepts and slopes were calculated; an intercept significantly different from 0 shows an absolute bias, and a slope significantly different from 1 shows a relative bias (Pansu et al., 2001).

\section{Results}

\subsection{Mineralization of added ${ }^{15} \mathrm{~N}$}

The model assumed that mineralized ${ }^{15} \mathrm{~N}$ (Figs. $3 \mathrm{~b}-5 \mathrm{~b}$ ) was the difference between the added ${ }^{15} \mathrm{~N}$ and the remaining ${ }^{15} \mathrm{~N}$. The largest part of this mineralized ${ }^{15} \mathrm{~N}$ was exported from the porous soil bags by root absorption, water leaching, or gaseous losses, since mineral ${ }^{15} \mathrm{~N}$ remaining in the bags accounted for only $1-3 \%$ of the mineralized ${ }^{15} \mathrm{~N}$ (Figs. 3c-5c). The results showed that the ${ }^{15} \mathrm{~N}$ mineralization rates decreased from low-altitude sites to higher sites (Figs. 3b-5b). About $63 \%$ of the added ${ }^{15} \mathrm{~N}$ was mineralized at the lowest sites, $\mathrm{A}(65)$ and $\mathrm{A}(165) ; 57 \%$ was mineralized at $\mathrm{A}(780)$, $47 \%$ at $\mathrm{A}(1800), 25 \%$ at $\mathrm{A}(3400)$, and $31 \%$ at $\mathrm{A}(3968)$. The ${ }^{14} \mathrm{C}$ mineralization at the end of incubation (Pansu et al., 2010) was higher, being about $80 \%$ of the added ${ }^{14} \mathrm{C}$ at the lowest sites $\mathrm{A}(65)$ and $\mathrm{A}(165), 75-80 \%$ at $\mathrm{A}(780)$ and $\mathrm{A}(1800)$, and $45 \%$ at the highest sites $\mathrm{A}(3400)$ and $\mathrm{A}(3968)$, showing the same trend for ${ }^{14} \mathrm{C}$ and ${ }^{15} \mathrm{~N}$, all values being well predicted by MOMOS. 
Table 4. Values and significance of additional parameters for MOMOS-N (this study).

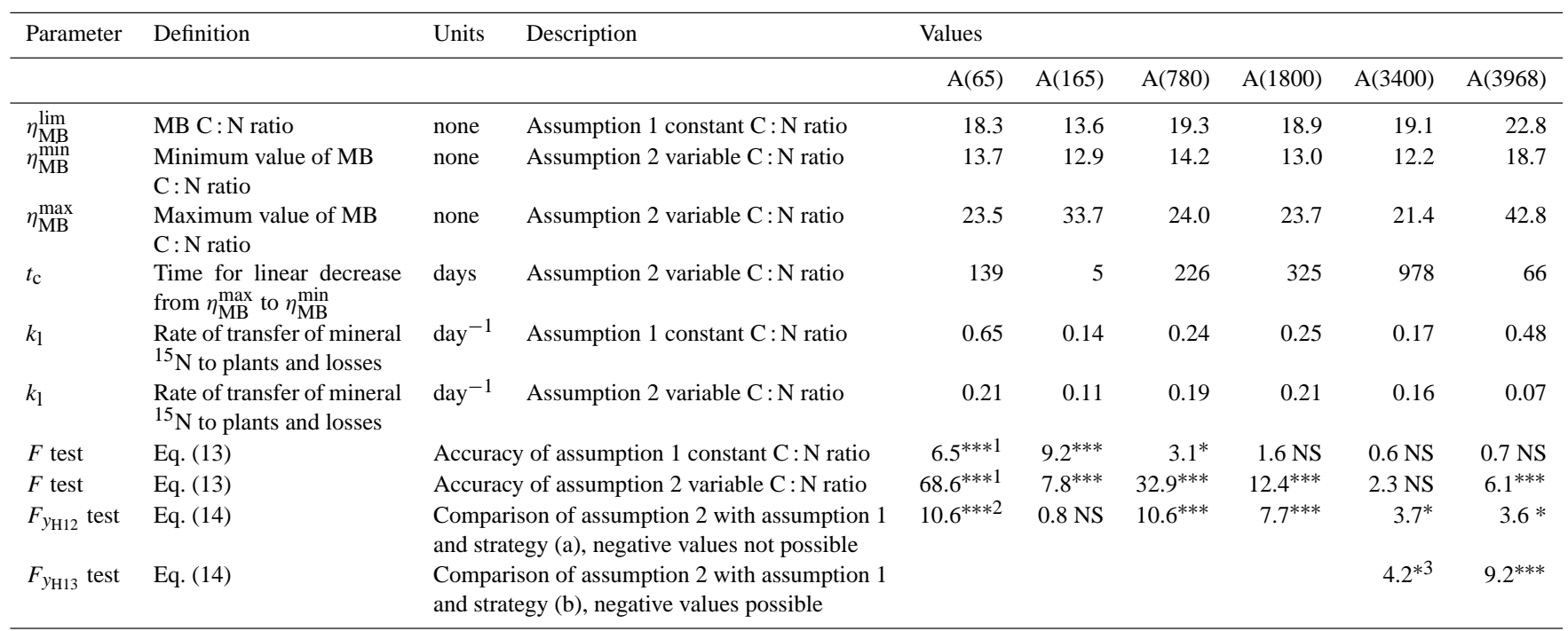

MB is the microbial biomass; ${ }^{1}$ model prediction significantly better than mean of measured values when $p<0.01(* * *), p<0.05(*)$, or not significantly better (NS); ${ }^{2}$ model prediction with assumption 2 and strategy (a) significantly better than model predictions with assumption 1 when $p<0.01(* * *), p<0.05(*)$, or not significantly better (NS); ${ }^{3}$ model prediction with assumption 2 and strategy (b) significantly better than model predictions with assumption 1 when $p<0.01\left(^{* * *}\right), p<0.05\left(^{*}\right)$, or strategy (b) not necessary (blank).
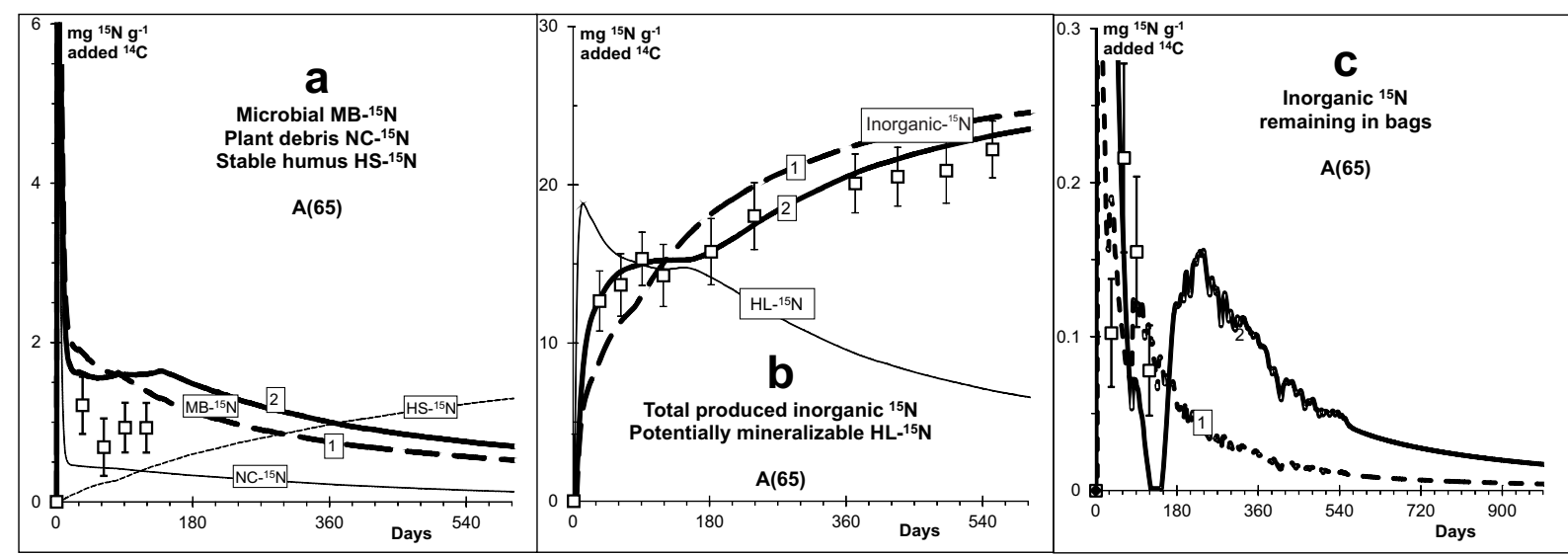

Fig. 3. Measured and simulated values at the lowest site (A65): squares are measured data with $95 \%$ confidence intervals of (a) MB- ${ }^{15} \mathrm{~N}$, (b) total inorganic- ${ }^{15} \mathrm{~N}$, (c) inorganic ${ }^{15} \mathrm{~N}$ remaining in bags; heavy dashed lines (1) are the simulated values using assumption 1 of constant $\mathrm{C}: \mathrm{N}$ ratio of $\mathrm{MB}$; heavy solid lines (2) are the simulated values using assumption 2 (variable $\mathrm{C}: \mathrm{N}$ ratio of $\mathrm{MB}$ ) and the first strategy (a); the light dotted line in (a) is the simulated ${ }^{15} \mathrm{~N}$ in stable humus HS, the light dashed line in (a) is the ${ }^{15} \mathrm{~N}$ remaining in the plant necromass (NC) and the light solid line in (b) is the potentially mineralizable ${ }^{15} \mathrm{~N}$ in the labile humus HL.

\subsection{Prediction of ${ }^{15} \mathrm{~N}$ mineralization using a constant MB C : $\mathbf{N}$ ratio}

Figure 2 shows the predictions of inorganic ${ }^{15} \mathrm{~N}$ using assumption 1 (Eq. 11) for the whole data set. No absolute bias was detected, but slopes significantly greater than 1 indicated a slight over-prediction of $6 \%$ for inorganic ${ }^{15} \mathrm{~N}(\diamond$, dashed line, and $y 1$ in Fig. 2a).

Nevertheless, the predicted values of ${ }^{15} \mathrm{~N}$ mineralization corresponded with the measured values only for low-altitude sites when $p<0.01$ for $\mathrm{A}(65)$ and $\mathrm{A}(165)$ and when $p<$ 0.05 for $A(780)$ (Table 4). Predicted values were within the
$95 \%$ confidence interval for the measured data for $\mathrm{A}(165)$ slightly overestimated between 360 and 500 days incubation for $\mathrm{A}(65)$ (heavy dashed line in Fig. 3b) and after five months incubation for A(780). For A(1800), the values were slightly underestimated for the first three months and overestimated by $20 \%$ after eight months of incubation (Fig. 4b). This effect was larger for the two higher sites where the predicted values agreed with the measurements only for the first year of incubation; after three years of incubation, the overestimate was $35 \%$ for $\mathrm{A}(3968)$ (Fig. 5b) and $50 \%$ for $\mathrm{A}(3400)$. 

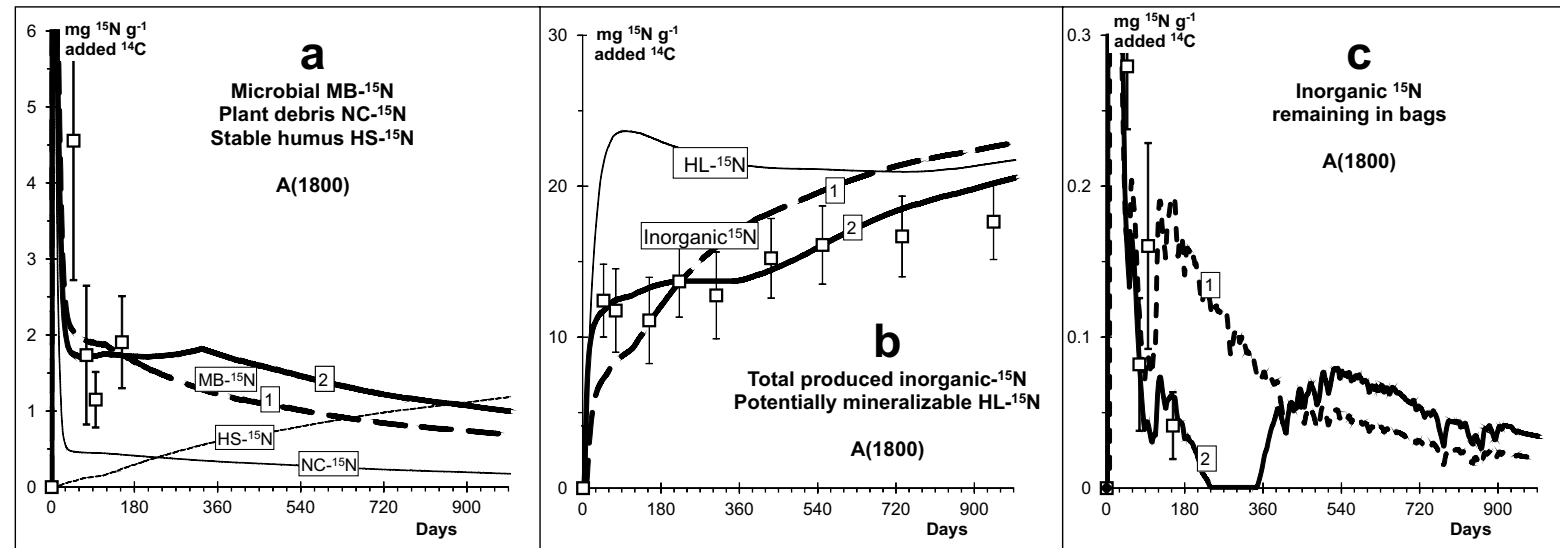

Fig. 4. Measured and simulated values for the mid-altitude site (A1800): squares are measured data with $95 \%$ confidence intervals of (a) MB- ${ }^{15} \mathrm{~N}$, (b) total inorganic- ${ }^{15} \mathrm{~N}$, (c) inorganic ${ }^{15} \mathrm{~N}$ remaining in bags; heavy dashed lines (1) are the simulated values using assumption 1 of constant $\mathrm{C}: \mathrm{N}$ ratio of $\mathrm{MB}$; heavy solid lines (2) are the simulated values using assumption 2 (variable $\mathrm{C}: \mathrm{N}$ ratio of $\mathrm{MB}$ ) and the first strategy, (a); the light dotted line in (a) is the simulated ${ }^{15} \mathrm{~N}$ in stable humus HS, the light dashed line in (a) is the ${ }^{15} \mathrm{~N}$ remaining in the plant necromass (NC) and the light solid line in (b) is the potentially mineralizable ${ }^{15} \mathrm{~N}$ in the labile humus HL.
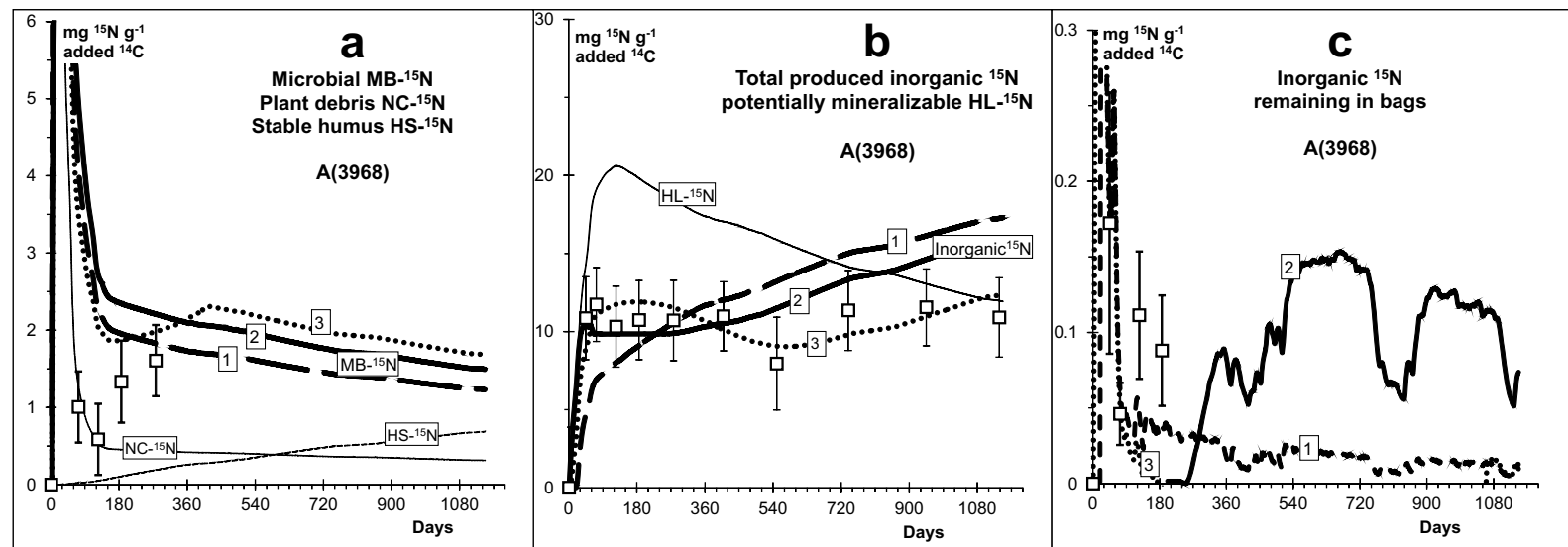

Fig. 5. Measured and simulated values for the high-altitude site (A3968): squares are measured data with $95 \%$ confidence intervals of (a) MB- ${ }^{15} \mathrm{~N}$, (b) total inorganic- ${ }^{15} \mathrm{~N}$, (c) inorganic ${ }^{15} \mathrm{~N}$ remaining in bags; heavy dashed lines (1) are the simulated values using assumption 1 of constant $\mathrm{C}: \mathrm{N}$ ratio of $\mathrm{MB}$; heavy solid lines (2) are the simulated values using assumption 2 (variable $\mathrm{C}: \mathrm{N}$ ratio of $\mathrm{MB}$ ) and the first strategy (a); heavy dotted lines (3) are the simulated values using assumption 2 and strategy (b); the light dotted line in (a) is the simulated ${ }^{15} \mathrm{~N}$ in stable humus HS, the light dashed line in (a) is the ${ }^{15} \mathrm{~N}$ remaining in the plant necromass (NC) and the light solid line in (b) is the potentially mineralizable ${ }^{15} \mathrm{~N}$ in the labile humus $\mathrm{HL}$.

\subsection{Prediction of ${ }^{15} \mathrm{~N}$ mineralization using variable $\mathrm{MB}$ $\mathrm{C}: \mathbf{N}$ ratio}

For the whole data set, the predicted values using assumption 2 (solid line, and $y 2$ in Fig. 2a) were close to those predicted using assumption 1 ( $\downarrow$, dashed line, and $y 1$ in Fig. 2a). The use of assumption 2 and strategy (a) improved predictions by reducing the over-prediction of inorganic- ${ }^{15} \mathrm{~N}$ to $3 \%$, but the two methods were not significantly different when $p<0.1$ ( $F$ test $=1.52$, Eq. 14 ). There was no over-prediction using assumption 2 and strategy (b) $(\Delta$, dotted line, and $y 3$ in Fig. 2a). In this case, the result of the $F$ test comparing the results for $y 1$ and $y 3$ (Eq. 14) was
1.89 , which is not significant when $p<0.05$, but is significant when $p<0.1$. For the whole data set, the predictions using the various assumptions and strategies can be considered as equivalent.

Assumption 2 (Eq. 12) gave more accurate predictions than assumption 1 in some particular situations, especially at high altitude. The predicted values of ${ }^{15} \mathrm{~N}$ mineralization using assumption 2 corresponded to the measured values when $p<0.01$ for five of the six sites, but only when $p<0.1$ for $\mathrm{A}(3400)$ (Eq. 13, Table 4). In five cases, the predicted values were significantly closer to the measured values (Eq. 14) when assumption 2 was used, when $p<0.01$ for $\mathrm{A}(65)$, $\mathrm{A}(780)$, and $\mathrm{A}(1800)$, and when $p<0.05$ for $\mathrm{A}(3400)$ and 
A(3968). There was no significant difference between the predictions given by the two assumptions for $\mathrm{A}(165)$. Strategy (b), allowing negative values for inorganic ${ }^{15} \mathrm{~N}$ and $M B{ }^{15} \mathrm{~N}$, predicted the measured values at the two highest sites significantly better than strategy (a), with $\mathrm{p}<0.01$ for $\mathrm{A}(3968)$ and when $p<0.05$ for $\mathrm{A}(3400)$ (Eq. 14, Table 4).

For $\mathrm{A}(65)$ (Fig. 3b), $\mathrm{A}(780)$ and $\mathrm{A}(1800)$ (Fig. 4b), the predicted values, using a variable $\mathrm{MB} C: \mathrm{N}$ ratio and truncating negative values (strategy (a)), were within the $95 \%$ confidence intervals of all the measurements. For A(3400), 10 of the 11 predicted values were within the $95 \%$ confidence intervals for both strategy (a) and strategy (b) (not shown). For A(3968) (Fig. 5b), 9 of the 11 predicted values were within the $95 \%$ confidence intervals of the measurements when strategy (a) was used (curve 2). All the predicted values were within the $95 \%$ confidence intervals when strategy (b) was used (curve 3).

\subsection{Prediction of other $\mathbf{N}$-labelled compartments}

Although measurements were only available for the first five periods, for the $\mathrm{MB}{ }^{15} \mathrm{~N}$ and inorganic- ${ }^{15} \mathrm{~N}$ remaining in the soil bags (see material and methods), the model predictions of MB- ${ }^{15} \mathrm{~N}$ were significantly similar to the measured values for the whole data set (Fig. 2b). The over-prediction of $7 \%$, calculated with assumption 1 for $\mathrm{MB}^{-15} \mathrm{~N}$ in the whole data set, was not significant (Fig. 2), and was again reduced to $5 \%$ by using assumption 2 and strategy (a). There was no overprediction using assumption 2 and strategy (b) (Fig. 2b).

For $\mathrm{A}(65)$, four of the five $\mathrm{MB}{ }^{15} \mathrm{~N}$ values were slightly over-predicted using assumption 1 (1 in Fig. 3a), and three were over-predicted using assumption 2 (2 in Fig. 3a). For $\mathrm{A}(165) \mathrm{MB}{ }^{15} \mathrm{~N}$ data were over-predicted (not shown). For $\mathrm{A}(780)$, the last $\mathrm{MB}{ }^{15} \mathrm{~N}$ value was slightly underpredicted (but within its wide confidence interval) whereas the three previous values were over-predicted (not shown). For A(1800) (Fig. 4a), 3 values of MB ${ }^{15} \mathrm{~N}$ were accurately predicted while one was under-predicted and one was overpredicted. For $\mathrm{A}(3400)$ (not shown), the $\mathrm{MB}{ }^{15} \mathrm{~N}$ were overpredicted. For A(3968) (Fig. 5a), 2 of the $5 \mathrm{MB}{ }^{15} \mathrm{~N}$ values were over-predicted. Although microorganisms are considered to be responsible for most transformations, their weight in terms of ${ }^{15} \mathrm{~N}$ stock is one of the lowest of the five MOMOS compartments. This was found to increase with altitude: after 540 days of incubation the stocks were 0.8 for $\mathrm{A}(65), 0.9$ for $\mathrm{A}(165)$ and $\mathrm{A}(780), 1.5$ for $\mathrm{A}(\mathrm{A} 800)$, and $2 \mathrm{mg}^{15} \mathrm{Ng}^{-1}$ (added $\left.{ }^{14} \mathrm{C}\right)$ for $\mathrm{A}(3400)$ and $\mathrm{A}(3968)$.

With assumption 1 or assumption 2 , all the predicted values for organic ${ }^{15} \mathrm{~N}$ remaining in the soil bags were close to the measured $95 \%$ confidence intervals, but there were no significant differences between the values for the two assumptions (Figs. 3c-5c).

In all cases, the model predicted a relatively large stock of ${ }^{15} \mathrm{~N}$ in the labile microbial metabolites (HL compartment), which was about $80 \%$ of the organic forms of ${ }^{15} \mathrm{~N}$ at the end of experiment and the main reserve of potentially mineralizable ${ }^{15} \mathrm{~N}$ (Figs. 3b-5b). At the lowest sites, $\mathrm{A}(65)$ and $\mathrm{A}(165)$, the net mineralization was highest and the HL- ${ }^{15} \mathrm{~N}$ was modelled as having about one-third of inorganic- $-{ }^{15} \mathrm{~N}$ after 540 days of incubation. The net mineralization then decreased and the HL- ${ }^{15} \mathrm{~N}$ reserve increased with altitude (except between $\mathrm{A}(3400)$ and $\mathrm{A}(3968)$ ); at 540 days of incubation the HL-/inorganic- ${ }^{15} \mathrm{~N}$ ratio was 0.6 for $\mathrm{A}(780), 0.9$ for $\mathrm{A}(1800), 2.3$ for $\mathrm{A}(3400)$, and 1.4 for $\mathrm{A}(3968)$.

The non-decomposed plant debris (NC in Fig. 1) was predicted as being the lowest ${ }^{15} \mathrm{~N}$ stock at the end of the experiment, slightly increasing with altitude and proportion of coarse fractions (Table 1); at 540 days of incubation, it was close to 0.1 for $\mathrm{A}(65), 0.2$ for $\mathrm{A}(165)$ and $\mathrm{A}(780), 0.3$ for $\mathrm{A}(1800)$, and $0.4 \mathrm{mg}{ }^{15} \mathrm{Ng}^{-1}$ (added ${ }^{14} \mathrm{C}$ ) for $\mathrm{A}(3400)$ and $\mathrm{A}(3968)$ (Figs. 3a-5a). Conversely, the amounts of ${ }^{15} \mathrm{~N}$ stabilized in the stable humified compartment (HS in Fig. 1)) were modelled as almost stable for the three low-altitude sites, and as decreasing with altitude and cold climate; at 540 days of incubation it was 1.2 for $\mathrm{A}(65), 1.0$ for $\mathrm{A}(165)$, 1.3 for $\mathrm{A}(780), 0.8$ for $\mathrm{A}(1800), 0.6$ for $\mathrm{A}(3400)$ and 0.4 for A(3968) (Figs. 3a-5a).

\section{Discussion}

\subsection{Relationship between $\mathrm{N}$ and $\mathrm{C}$ cycles}

These modelling results provide a positive answer to the first questions raised in the introduction regarding the validity of the extensions to the model for the $\mathrm{N}$ cycle. (1) Can the rates of direct enzymatic $\mathrm{C}$ and $\mathrm{N}$ assimilation be considered to be the same? Yes, this appears to be the case because all the parameters defined for the MOMOS-C model and their dependence on climate, quality of dead plant materials and soil texture were retained for modelling the $\mathrm{N}$ cycle. This study showed that there was a strong link between the transfer processes of $\mathrm{C}$ and $\mathrm{N}$ from natural organic compounds. (2) Can the transfers of $\mathrm{C}$ by microbial mortality and respiration cause simultaneous transfers of $\mathrm{N}$ into labile humus and inorganic forms to balance the MB C: $\mathrm{N}$ ratio? Yes, this modelling study demonstrated the simultaneous MB-N transfer into labile humus (HL compartment in Fig. 1) by microbial mortality and into inorganic $\mathrm{N}$ by ammonification. All the microbial exchanges caused a progressive decrease of $\mathrm{C}: \mathrm{N}$ ratios in the $\mathrm{MB}$ and $\mathrm{HL}$ compartments (Fig. 1), owing to $\mathrm{CO}_{2}$ losses by microbial respiration and a relative increase in the amounts of transferred ${ }^{15} \mathrm{~N}$. (3) Can the assimilation of inorganic $\mathrm{N}$ be modelled to sustain microbial activity in the case of an $\mathrm{N}$ deficit during conversion of organic forms? Yes, microbial immobilization of inorganic ${ }^{15} \mathrm{~N}$ was modelled mainly from one to a few days of incubation, corresponding to the highest ${ }^{14} \mathrm{C}$ flow from the VL compartment (Fig. 1), with the immobilization period increasing from 3 days in low-altitude sites to 8 days in high-altitude sites. 
This study also provided an answer to the question of microorganism homeostasis: does the microbial biomass $\mathrm{C}: \mathrm{N}$ ratio remain constant or does it vary with incubation time and in different ecosystems? The model predictions using the assumption that the MB $\mathrm{C}: \mathrm{N}$ ratio remains constant throughout the incubation period gave MB C:N values (Table 4) ranging from 13.6 at the tropical savannah site, $\mathrm{A}(165)$, to 22.8 at the highest site, $\mathrm{A}(3968)$, for a ${ }^{14} \mathrm{C}:{ }^{15} \mathrm{~N}$ ratio of 32 for the substrate (Table 2). These could be considered high since the $\mathrm{C}: \mathrm{N}$ ratio is generally considered to be within a restricted range from about 5 to 15 (Manzoni and Porporato, 2009). The microbial cultures of Nicolardot et al. (1986) had $\mathrm{C}: \mathrm{N}$ ratios in the range 5.2-12.7, depending on the substrate $\mathrm{C}: \mathrm{N}$ ratios used in their laboratory conditions. Other works such as that of Wallander et al. (2003) found MB C-N ratios of between 18.5 (for a soil $\mathrm{C}: \mathrm{N}$ ratio of 16.9) and 21.9 (for a soil C: $\mathrm{N}$ ratio of 30.4); Bottner et al. (2006) measured MB ${ }^{14} \mathrm{C}:{ }^{15} \mathrm{~N}$ ratios of $7.9 \pm 1.3$ for a substrate ${ }^{14} \mathrm{C}:{ }^{15} \mathrm{~N}$ ratio of 26.8, and $\mathrm{MB}{ }^{14} \mathrm{C}:{ }^{15} \mathrm{~N}$ ratios of $33.9 \pm 7.5$ for a substrate ${ }^{14} \mathrm{C}:{ }^{15} \mathrm{~N}$ ratio of $130(2 \times 10$ measurements in two sites $)$. The MB-C: $\mathrm{N}$ ratios found in this paper were close to the measured total $\mathrm{C}: \mathrm{N}$ ratios (Table 1) for the six sites, suggesting that the quality of living and dead organic materials converge to similar values after long fallow periods.

Especially for the high-altitude sites in this study, the predicted values were significantly more accurate when the MB $\mathrm{C}: \mathrm{N}$ ratio was reduced linearly with the incubation time. The MB C : $N$ ratio was highest with excess $\mathrm{C}$ at the start of incubation, which encouraged microbial immobilization of inorganic $\mathrm{N}$. The $\mathrm{C}: \mathrm{N}$ value decreased linearly with time to its minimum value associated with a reduction in $\mathrm{C}$ mineralization, with a lower slope at higher altitudes. The minimum values found for MB $\mathrm{C}: \mathrm{N}$ ratios (Table 4) were in the commonly accepted range, except at the high-altitude site $\mathrm{A}(3968)$, where $\mathrm{CO}_{2}-\mathrm{C}$ respiration was reduced by lower temperatures. This study shows that it is possible to model the climatic role in $\mathrm{C}$ and $\mathrm{N}$ storage: cold and wet climates cause the accumulation of $\mathrm{C}$ with high $\mathrm{C}: \mathrm{N}$ values, in accordance to Wallander et al. (2003) for Norway. Bottner et al. (2006) showed that total respired $\mathrm{CO}_{2-}{ }^{14} \mathrm{C}$ was lower for nitrogen-poor straw than for nitrogen-rich straw. This was partly explained by an increase in microbial mortality $\left(k_{\mathrm{MB}}\right.$ rate) which could increase the HL reserve, which is richer in $\mathrm{N}$ than stable $\mathrm{NC}$ and can sustain MB and the microbial conversion to inorganic $\mathrm{N}$. This study illustrates that more ${ }^{15} \mathrm{~N}$ was retained in plant debris at higher altitudes (and in soils with coarse texture) and that there was a lower concentration of ${ }^{15} \mathrm{~N}$ and an increase in ${ }^{14} \mathrm{C}:{ }^{15} \mathrm{~N}$ ratios in stable humified compounds in these conditions. This was associated with a slight increase in the predicted values for the stock of living microorganisms in cold and wet climates which could cause significant release of $\mathrm{CO}_{2}$ associated with higher temperature, from the high reserves of $\mathrm{C}$ in these conditions, confirming risks already mentioned (Gundelwein et al., 2007; Reichstein et al., 2013).
Except for $\mathrm{A}(165)$ and $\mathrm{A}(3968)$, the slopes of the MB $\mathrm{C}: \mathrm{N}$ ratio vs. time decreased with increasing altitude $\left(t_{\mathrm{c}}\right.$ in Table 4). This appears to be consistent with a decrease in metabolic rates with temperature (Eqs. 1 and 2).

Allowing negative values for inorganic ${ }^{15} \mathrm{~N}$ (immobilization of inorganic ${ }^{14} \mathrm{~N}$ ) only significantly improved the predicted values for ${ }^{15} \mathrm{~N}$ mineralization at the two high-altitude sites, especially at the highest site. For these sites, the model predicted microbial immobilization of $\mathrm{N}$ not only at the start of incubation, but also later on during incubation. This strange behaviour needs to be investigated by further experiments.

\subsection{Ecological consistency, accuracy and robustness}

This study established that there is a strong link between $\mathrm{C}$ and $\mathrm{N}$ assimilation, the only difference between the model for $\mathrm{C}$ and the model for $\mathrm{N}$ being the modelling of the microbial exchanges to and from inorganic compounds. $\mathrm{C}$ is removed from the system as the $\mathrm{CO}_{2}$ from microbial respiration (Eqs. 5 and 6), while inorganic $\mathrm{N}$ recycles rapidly in the soil in equilibrium with the microbial N. This confirms that $\mathrm{MB}$ acts as a very active, short-term reserve, temporarily storing $\mathrm{C}$ and $\mathrm{N}$, releasing $\mathrm{C}$ by respiration, producing $\mathrm{C}+\mathrm{N}$ labile humus compounds (HL in Fig. 1) by microbial mortality and exudation, recycling the major part of this HL, and converting to and from inorganic forms of N. For the whole data set, MOMOS appears robust for the prediction of inorganic $\mathrm{N}$ available for plant growth. As a first approximation, microorganism homeostasis can be assumed, giving accuracy within about $6 \%$. Consequently, using the simpler assumption 1 , of a constant $\mathrm{C}: \mathrm{N}$ ratio (Eq. 11), can give predictions that are sufficiently robust (Fig. 2) for modelling on a regional scale.

However, more precise studies, especially in cold and wet areas, require microorganisms to be considered as not being really homeostatic. The decomposition processes are probably initiated by fungi with a high $\mathrm{C}: \mathrm{N}$ ratio and continued by bacteria or other microorganisms with lower $\mathrm{C}: \mathrm{N}$ ratios. The fumigation-extraction used in this work is one of the most popular methods for global microbial quantification (Satyanarayana et al., 2012) but it is subject to errors which could explain some of the discrepancies between the predictions and measurements of ${ }^{14} \mathrm{C}$ - and ${ }^{15} \mathrm{~N}-\mathrm{MB}$ in this study. Fumigation and extraction must be made using fresh samples preserved at $4{ }^{\circ} \mathrm{C}$. Unfortunately, the experimental plots were in remote tropical sites which were sometimes not very accessible. It was not always possible to treat the samples immediately after sampling, and it was not always easy to maintain the icebox at $4{ }^{\circ} \mathrm{C}$. The burying of porous soil bags at $5 \mathrm{~cm}$ was sometimes affected by erosion, and the contact with fauna and plant roots was not always uniform. This may have resulted in significant errors in the measurement of $\mathrm{MB}$, one of the compartments with the lowest ${ }^{15} \mathrm{~N}$ stocks. For the application of the model at regional scales, it was 
encouraging that (1) MB predictions appeared to be unbiased for the whole data set (Fig. 2b) and (2) that the errors in MB measurements at some sites did not greatly affect the accuracy of predictions of inorganic- ${ }^{15} \mathrm{~N}$; the model appears to be robust for these predictions which are essential for evaluating the life cycle.

The MOMOS model is based on the principle of parallel $\mathrm{C}$ and $\mathrm{N}$ assimilation (see PAR models in the introduction), as it includes simultaneous, direct microbial assimilation of plant and humus compounds, ammonium production by microorganisms and, possibly, microbial assimilation of the ammonium produced. This work builds on the proposition underlying MOMOS C that microorganisms play a key role in the decomposition process. For the $\mathrm{N}$ cycle, the model requires only one two-way path between $\mathrm{MB}$ and inorganic $\mathrm{N}$ based on fitting the $\mathrm{C}: \mathrm{N}$ ratio of $\mathrm{MB}$ (the $\mathrm{C}: \mathrm{N}$ ratio of the humus compartments are predicted, the $\mathrm{C}: \mathrm{N}$ ratio of necromass and its stable VS compartment are measured or estimated, and the $\mathrm{C}: \mathrm{N}$ ratio of $\mathrm{VL}$ is calculated by the balance Eq. 9). The other $\mathrm{C}$ and $\mathrm{N}$ models (see Introduction) generally derive the $\mathrm{N}$ cycle by dividing the $\mathrm{C}$ values of each compartment by a given $\mathrm{C}: \mathrm{N}$ ratio and they propose several paths for mineralization and immobilization of N. For example, Parton et al. (1987) proposed fixing the $\mathrm{C}: \mathrm{N}$ ratios at 150 for the structural compartment, 10-25 for the metabolic compartment, 8 for the active compartment, 11 for the slow compartment, and 11 for the passive-compartment, with five paths for mineralization and immobilization, which is less parsimonious in parameters than MOMOS as described in this study. The previously proposed MOMOS-N (Pansu et al., 1998) also attempted to simplify the model parameterization but was less parsimonious than the equation system described in this paper, which should fill a gap (see Introduction) in modelling "direct microbial control over decomposition".

Acknowledgements. This study was part of the bilateral FranceVenezuela cooperation programme ECOS-NORD V07A01 (Modelling soil organic mater in Venezuelan ecosystems and its application to fertility management and carbon sequestration) and financed in part by CDCHT-ULA (project C-765-95-01-B) and FONACIT (F-2002000424). We should like to thank the experts who contributed to the Biogeoscience discussion website http://www.biogeosciences-discuss.net/: Nicolardot (Agrosup, Dijon, France) for his constructive comments on microbial $\mathrm{C}: \mathrm{N}$ ratio, A. Hammoudi and O. Iosifescu (Institute of mathematics and modelling, Université Montpellier 2, France) for their analysis of the MOMOS equation system, S. D. Allison (University of California, Irvine, USA) and three anonymous referees for their constructive reviews for Biogeoscience and Biogeoscience discussion.

Edited by: F. X. Meixner

\section{References}

Barraclough, D.: The direct or MIT route for nitrogen immobilization: a $15 \mathrm{~N}$ mirror image study with leucine and glycine, Soil Biol. Biochem., 29, 101-108, 1997.

Bottner, P., Pansu, M., Sarmiento, L., Hervé, D., CallisayaBautista, R., and Metselaar, K.: Factors controlling decomposition of soil organic matter in fallow systems of the high tropical Andes: a field simulation approach using ${ }^{14} \mathrm{C}$ and ${ }^{15} \mathrm{~N}-$ labelled plant material Soil Biol. Biochem., 38, 2162-2177, doi:10.1016/j.soilbio.2006.01.029, 2006.

Bradbury, N. J., Witmore, A. P., Hart, P. B. S., and Jenkinson, D. S.: Modelling the fate of nitrogen in crop and soil in the years following application of $15 \mathrm{~N}$-labelled fertilizer to winter wheat, J. Agr. Sci., 121, 363-379, 1993.

Brookes, P. C., Landman, A., Pruden, G., and Jenkinson, D. S.: Chloroform fumigation and the release of soil nitrogen : a rapid direct extraction method to measure microbial biomass nitrogen in soil, Soil Biol. Biochem., 17, 837-842, 1985.

Burnham K. P. and Anderson D. R.: Model Selection and Multimodel Inference A Practical Information-Theoretic Approach, Second Edition Springer, Eidelberg, New-York, Tokyo, 1998.

Carter, M. R., Parton, W. J., Rowland, I. C., Schultz, J. E., and Steed, G. R.: Simulation of soil organic carbon and nitrogen changes in cereal and pasture systems of southern Australia, Austr. J. Soil Res., 31, 481-491, 1993.

Coûteaux, M. M., Sarmiento, L., Bottner, P., Acevedo, D., and Thiéry, J. M.: Decomposition of standard plant material along an altitudinal transect $(65-3968 \mathrm{~m})$ in the tropical Andes, Soil Biol. Biochem., 34, 69-78, 2002.

Dou, Z. and Fox, R. H.: Using NCSWAP to simulate seasonal nitrogen dynamics in soil and corn, Plant and Soil, 177, 235-247, 1995.

Franko, U.: Simulation of carbon and nitrogen dynamics in rural areas, Landbauforschung Volkenrode, 46, 114-120, 1996.

Garnier, P., Néel, C., Mary, B., and Lafolie, F.: Evaluation of a nitrogen transport and transformation model in a bare soil, Europ. J. Soil Sci., 52, 253-268, 2001.

Gundelwein, A., Müller-Lupp, T., Sommerkorn, M., Haupt, E. T. K., Pfeiffer, E. M., and Wiechmann, H.: Carbon in tundra soils in the Lake Labaz region of arctic Siberia, Europ. J. Soil Sci., 58, 1164-1174. 2007.

Joergensen, R. G. and Mueller, T.: The fumigation-extraction method to estimate soil microbial biomass: Calibration of the k(EN) value, Soil Biol. Biochem., 28, 33-37, 1996.

Kaboré, W.T., Pansu, M., Hien, E., Brunet, D., Barthès, B.G., Houot, S., Coulibaly, A., Zombré, P., Thuriès, L., and Masse, D.: Near infrared reflectance spectroscopy applied to model the transformation of added organic materials in soil, J. Near Infrared Spectroscopy, 20, 339-351, 2012.

Kemmitt, S., Lanyon, C., Waite, I., Wen, Q., Addiscott, T. M., Bird, N. R. A., O'Donnell, A., and Brookes, P.: Mineralization of native soil organic matter is not regulated by the size, activity or composition of the soil microbial biomass - a new perspective, Soil Biol. Biochem., 40, 61-73, 2008.

Lin, B.-L., Sakoda, A., Shibasaki, R., Goto, N., and Suzuki, M.: Modelling a global biogeochemical nitrogen cycle in terrestrial ecosystems, Ecol. Modell., 135, 89-110, 2000. 
Manzoni, S. and Porporato, A.: Soil carbon and nitrogen mineralization: Theory and models across scales, Soil Biol. Biochem., 41, 1355-1379, 2009.

Mueller, T., Magid, J., Jensen, L. S., Svendsen, H., and Nielsen, N. E.: Soil $\mathrm{C}$ and $\mathrm{N}$ turnover after incorporation of chopped maize, barley straw and blue grass in the field: Evaluation of the DAISY soil-organic-matter submodel, Ecol. Modell., 111, 1-15, 1998.

Neill, C. and Gignoux, J.: Soil organic matter decomposition driven by microbial growth: a simple model for a complex network of interactions, Soil Biol. Biochem., 38, 803-811, 2006.

Nicolardot B., Guiraud G., Chaussod R., and Catroux G.: Minéralisation dans le sol de matériaux microbiens marqués au carbone 14 et à l'azote 15 : quantification de l'azote de la biomasse microbienne, Soil Biol. Biochem., 18, 263-273, 1986.

Nicolardot, B., Recous, S., and Mary, B.: Simulation of C and N mineralisation during crop residue decomposition: a simple dynamic model based on the $\mathrm{C}: \mathrm{N}$ ration of the residues, Plant Soil, 83, 83-103, 2001.

Pansu, M. and Gautheyrou, J.: Handbook of soil analysis - Mineralogical, organic and inorganic methods, Springer, Berlin, Heidelberg, New-York, 993 pp., 2006.

Pansu, M., Sallih, Z., and Bottner, P.: Modelling of soil nitrogen forms after organic amendments under controlled conditions, Soil Biol. Biochem., 30, 19-29, 1998.

Pansu, M., Thuriès, L., Larré-Larrouy, M. C., and Bottner, P.: Predicting $\mathrm{N}$ transformations from organic inputs in soil in relation to incubation time and biochemical composition, Soil Biol. Biochem., 35, 353-363, 2003.

Pansu M., Gautheyrou J., and Loyer J. Y.: Soil Analysis - Sampling, Instrumentation and Quality control, Balkema, Lisse, Abington, Exton, Tokyo, 489 pp., 2001.

Pansu, M., Bottner, P., Sarmiento, L., and Metselaar, K.: Comparison of five soil organic matter decomposition models using data from a ${ }^{14} \mathrm{C}$ and ${ }^{15} \mathrm{~N}$ labeling field experiment, Global Biogeochem. Cy., 18, GB4022, doi:4010.1029/2004GB002230, 2004.

Pansu, M., Martineau, Y., and Saugier, B.: A modelling method to quantify in situ the input of carbon from roots and the resulting $\mathrm{C}$ turnover in soil, Plant Soil, 317, 103-120, doi:10.1007/s11104008-9791-1, 2009.

Pansu, M., Sarmiento, L., Rujano, M. A., Ablan, M., Acevedo, D., and Bottner, P.: Modeling Organic transformations by MicroOrganisms of Soils in six contrasting ecosystems: validation of the MOMOS model, Global Biogeochem. Cy., 24, GB1008, doi:10.1029/2009GB003527, 2010.
Parton, W. J., Schimel, D. S., Cole, C. V., and Ojima, D. S.: Analysis of factors controlling soil organic matter levels in great plains grasslands, Soil Sci. Soc. Am. J., 51, 1173-1179, 1987.

Penning de Vries, F. W. T., Jansen, D. M., ten Berge, H. F. M., and Bakema, A.: Simulation of ecophysiological processes of growth in several annual crops, Pudoc, Wageningen, 271 pp., 1989.

Quemada, M. and Cabrera, M. L.: CERES-N model predictions of nitrogen mineralized from cover crop residues, Soil Sci. Soc. Am. J., 59, 1059-1065, 1995.

Reichstein, M., Bahn, M., Ciais, P., Frank, D., Mahecha, M.D., Seneviratne, S.I., Zscheischler, J., Beer, C., Buchmann, N., Frank, D.C., Papale, D., Rammig, A., Smith, P., Thonicke, K. van der Velde, M., Vicca, S., Walz, A., and Wattenbach, M.: Climate extremes and the carbon cycle, Nature, 500, 287-295, doi:10.1038/nature12350, 2013.

Richter, J. and Benbi, D. K.: Modeling of nitrogen transformations and translocations, Plant Soil, 181, 109-121, 1996.

Satyanarayana, T., Bhavdish, N. J.,and Prakash, A.: Microorganisms in Environmental Management. Microbes and Environment, Springer, 2012.

Sterner, R. W. and Elser, J. J.: Ecological stoichimometry. The biology of elements from molecules to biosphere, edited by: Press, P. U., Princeton and Oxford, 2002.

Thuriès, L., Pansu, M., Larré-Larrouy, M. C., and Feller, C.: Biochemical composition and mineralization kinetics of organic inputs in a sandy soil, Soil Biol. Biochem., 34, 239-250, 2002.

Todd-Brown, K. E. O., Hopkins, F. M., Kivlin, S. N., Jennifer, M., Talbot, J. M., and Allison, S. D.: A framework for representing microbial decomposition in coupled climate models, Biogeochemistry, 109, 19-33, doi:10.1007/s10533-011-9635-6, 2012.

Treseder, K. K., Balser, T. C., Bradford, M. A., Brodie, E. L., Dubinsky, E. A., Eviner, V. T., Hofmockel, K. S., Lennon, J. T., Levine, U. Y., MacGregor, B. J., Pett-Ridge, J., and Waldrop, M. P.: Integrating microbial ecology into ecosystem models: challenges and priorities, Biogeochemistry, 109, 7-18, doi:10.1007/s10533011-9636-5, 2011

Van Veen, J. A., Ladd, J. N., and Amato, M.: Turnover of carbon and nitrogen through the microbial biomass in a sandy loam and a clay soil incubated with $\left[{ }^{14} \mathrm{C}(\mathrm{U}]\right.$ glucose and $\left[{ }^{15} \mathrm{~N}\right]\left(\mathrm{NH}_{4}\right)_{2} \mathrm{SO}_{4}$ under different moisture regimes, Soil Biol. Biochem., 17, 747$756,1985$.

Wallander, H., Nilsson, L. O., Hagerberg, D., and Rosengren, U. Direct estimates of $\mathrm{C}: \mathrm{N}$ ratios of ectomycorrhizal mycelia collected from Norway spruce forest soils, Soil Biol. Biochem., 35, 997-999, 2003. 